\title{
RADIOLOGICAL ANALYSIS OF OLFACTORY FOSSA DEPTH: A TERTIARY CARE HOSPITAL BASED STUDY
}

\author{
Shrestha $B L^{1^{*}}$, Karmacharya $S^{2}$, Shrestha $K S^{3}$
}

\section{Affiliation}

1. Associate Professor, Department of ENT-HNS, Dhulikhel Hospital, Kathmandu University Hospital, Kavre, Nepal

2. Final Year Resident, Department of ENT-HNS, Dhulikhel Hospital, Kathmandu University Hospital, Kavre, Nepal

3. Lecturer, Department of ENT-HNS, Dhulikhel Hospital, Kathmandu University Hospital, Kavre, Nepal

\section{ARTICLE INFO}

\section{Article History}

\section{Received : 11 November, 2018 \\ Accepted : 11 December, 2018 \\ Published : 31 December, 2018}

(c) Authors retain copyright and grant the journal right of first publication with the work simultaneously licensed under Creative Commons Attribution License CC - BY 4.0 that allows others to share the work with an acknowledgment of the work's authorship and initial publication in this journal.

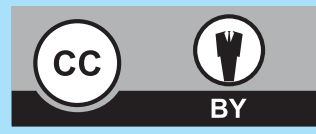

ORA 93

DOI: $\underline{10.3126 / \text { bjhs.v3i3.22193 }}$

\author{
* Corresponding Author \\ Dr. Bikash lal Shrestha \\ Associate Professor \\ Department of ENT-HNS \\ Dhulikhel Hospital, Kathmandu University Hospital \\ Email: bikash001@hotmail.com \\ ORCID ID: https://orcid.org/0000-0002-9214-2393
}

\section{ABSTRACT}

\section{Introduction}

Computed tomogram (CT) of nose and paranasal sinuses provides the detailed knowledge of depth of olfactory fossa as per Keros' classification, which is important in endoscopic sinus surgery.

\section{Objective}

To analyze the types and frequency of depth of olfactory fossa in Nepalese population.

\section{Methodology}

This was a longitudinal study conducted from $1^{\text {st }}$ May to $30^{\text {th }}$ August 2018. Coronal CT scans of nose and paranasal sinuses were taken for analysis of olfactory fossa depth. The landmarks like infraorbital foramen, point of articulation of medial ethmoidal roof with lateral lamella of cribriform plate (MERP) and lowest point on the cribriform plate (CP) were taken. The lateral lamella of cribriform plate (LLCP) was calculated by subtracting $\mathrm{CP}$ height from MERP height (MERP-CP = LLCP).

\section{Results}

There were total 101 patients included. The distribution of age was $33.72 \pm 15.15$ years. The keros' type I was the most common (86.1\%). Regarding the olfactory fossa depth, right side was deeper in male whereas in females, the left side was deeper, but overall right side was deeper in 52(51.5\%) patients.

\section{Conclusions}

Type I Keros' was the most common whereas type III Keros' was the least common. A deep olfactory fossa is more common on right.

\section{KEYWORDS}

Cribriform plate, ethmoidal roof, lateral lamella of cribriform plate, olfactory fossa depth

\section{Citation}

Shrestha BL, Karmacharya S, Shrestha KS. Radiological Analysis of Olfactory Fossa Depth: A Tertiary Care Hospital Based Study. BJHS 2018;3(3)7: 575 - 579. 


\section{INTRODUCTION}

For the endoscopic sinus surgery the detailed anatomical knowledge of nose and paranasal sinus is important. The knowledge is mainly gained by the computed tomogram of nose and paranasal sinuses. Though there are several other important surgical landmarks, the landmark of olfactory fossa is very important during sinus surgeries to avoid iatrogenic injury to anterior skull base.

The olfactory fossa is occupied by the olfactory nerve and bulb. It lies in the most infero-medial portion of the anterior cranial fossa. The crista galli forms the longitudinal limb above the horizontal limb and the perpendicular plate lies below it. ${ }^{1}$

The fovea ethmoidalis (FE) is the major part in formation of the roof of the ethmoid bony labyrinth that separates the ethmoidal air cells from the anterior cranial fossa. It articulates medially with the lateral lamella of the cribriform plate (LLCP). The shape of the fovea is determined by the joining angle between FE and LLCP. ${ }^{2}$

The LLCP is the thinnest bone, so it is the most vulnerable site for iatrogenic injury during functional endoscopic sinus surgery (FESS).

In 1962, Keros' had described the different heights of the horizontal level of the cribriform plate. As per Keros' classification, there are 3 types of olfactory fossa depth depending on the length of the LLCP. This thin (mainly vertical) plate of bone is connecting the lateral wall of cribriform plate with fovea ethmoidalis.

The three types of olfactory fossa are: Type I is 1-3 mm deep in which the lateral lamella is short, and the ethmoid roof and cribriform plate are almost in the same plane. Type II (most common) is 4 to $7 \mathrm{~mm}$ deep, and the lateral lamella is longer. In type III, it is 8-16 mm deep, and the ethmoid roof lies significantly above the cribriform plate. According to Keros, the more the height of LLCP, the greater the risk of iatrogenic injury during endoscopic sinus surgery. ${ }^{7}$ Therefore, the type III is at risk during endoscopic sinus surgery for iatrogenic injury.

Since, there are not many studies done in Nepal regarding olfactory fossa depth, this study explores the variations of olfactory fossa depth which will help during endoscopic sinus surgery. So, the main aim our study is to analyze the types and frequency of olfactory fossa depth.

\section{METHODOLOGY}

This was a prospective, longitudinal study conducted in the department of Otorhinolaryngology and Head and Neck surgery, Dhulikhel Hospital, Kathmandu University from $1^{\text {st }}$ May 2018 to $30^{\text {th }}$ August 2018. The ethical approval was taken from institutional review committee.

All patients $>/=18$ years of age who underwent CT Scans of the nose and paranasal sinuses were included in the study whereas patients with previous sinus surgery, age $<18$ years, maxillofacial trauma, sinonasal malignancy, congenital anomaly and CT images of low resolution were excluded.
The one hundred one consecutive patients who underwent CT scan of nose and paranasal sinuses and fitted in the inclusion criteria were taken for the study.

CT scans were performed in 128 slice Siemens somatom perspective machine. Patient was positioned in supine position and using the parameters $-130 \mathrm{kV}, 145 \mathrm{mAs}$, and scan time of 3.5 seconds, a volumetric axial CT scan was taken with $3 \mathrm{~mm}$ slices thickness from the frontal sinus to the floor of maxillary sinus. Multiplanar reconstruction was done using $1 \mathrm{~mm}$ thin slices with $0.5 \mathrm{~mm}$ interval and images were obtained in all planes. For the depth of olfactory fossa calculation, coronal images were used. All the observations were performed by one person to avoid observer bias.

The positions of cribriform plate and ethmoidal roof were calculated relative to orbital floor as shown by the infraorbital foramen (a plane passing through the two foramina was used (IOP)). Two reference points were chosen at the skull base. They were: point of articulation of medial ethmoidal roof with lateral lamella of cribriform plate (MERP) and lowest point on the cribriform plate (CP) as shown in figure 1.

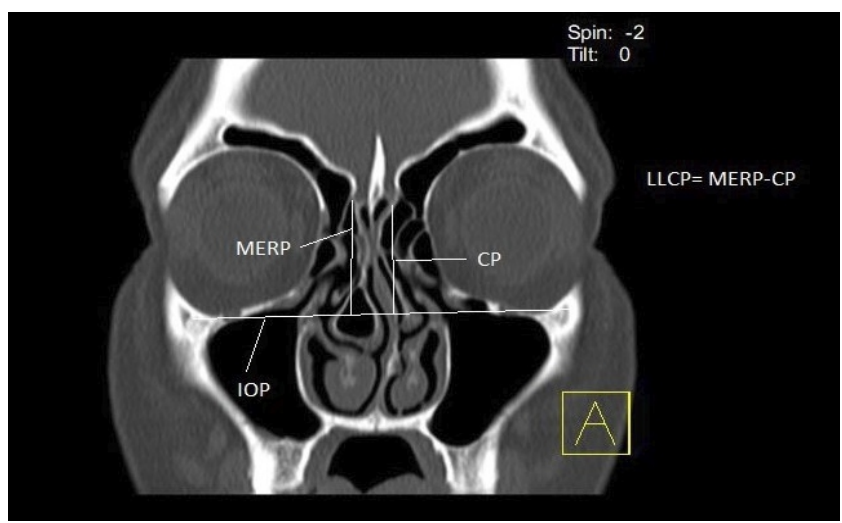

Figure 1: Showing the measurement of different landmarks in CT Scan.

Vertical height from MERP (MERP height) and vertical height from CP (CP height) to the horizontal plane through infraorbital foramen were measured on each side (IOP). The LLCP was calculated by subtracting CP height from MERP height (MERP-CP = LLCP). ${ }^{8}$ The LLCP was classified according to Keros classification but with modification. In type I we included 0-3.99mm, in type II 4-7 $\mathrm{mm}$ and in type III >7 mm as there was deficit of $1 \mathrm{~mm}$ in type I to type II and type II to type III. The LLCP was compared on both sides in males and females.

For the statistical analysis, statistical package for social sciences version 23 (SPSS) was used. The frequency table was used to evaluate the different variables using the descriptive statistical methods (mean, standard deviation and percentage).

\section{RESULTS}

There were total 101 patients included in the study. The distribution of age was $33.72+/-15.15$ years. Regarding the gender, there were 51 males and 50 females. 
The Keros' variation type I was the most common in both right and left side as shown in table 1.

Table 1. Showing the Keros' variation.

\begin{tabular}{|c|c|c|c|}
\hline Side & Type I & Type II & Type III \\
\hline Right $(n=101)$ & $88(87.1 \%)$ & $12(11.9 \%)$ & $1(1 \%)$ \\
\hline Left $(n=101)$ & $86(85.1 \%)$ & $15(14.9 \%)$ & $0(0 \%)$ \\
\hline Total $(n=202)$ & $174(86.1 \%)$ & $27(13.4 \%)$ & $1(0.5 \%)$ \\
\hline
\end{tabular}

Regarding the gender distribution of Keros' variation, Type I was the commonest in both sides and both genders as shown in Table 2.

Table 2. Showing the gender related Keros' variation in
right and left side.
\begin{tabular}{|r|r|r|r|r|r|r|r|r|}
\hline \multicolumn{7}{|c|}{ Right } \\
\cline { 2 - 8 } & \multicolumn{7}{|c|}{ Lide } \\
\hline Gender & Type I & Type II & Type III & Total & Type I & $\begin{array}{r}\text { Type } \\
\text { II }\end{array}$ & $\begin{array}{r}\text { Type } \\
\text { III }\end{array}$ & Total \\
\hline Male & $42(41.7 \%)$ & $8(7.9 \%)$ & $1(0.9 \%)$ & $51(50.5 \%)$ & $45(44.6 \%)$ & $6(5.9 \%)$ & $0(0 \%)$ & $51(50.5 \%)$ \\
\hline Female & $46(45.5 \%)$ & $4(3.96 \%)$ & $0(0 \%)$ & $50(49.5 \%)$ & $41(40.6 \%)$ & $9(8.9 \%)$ & $0(0 \%)$ & $50(49.5 \%)$ \\
\hline
\end{tabular}

Regarding the depth of the olfactory fossa, right side was deeper in males whereas the left side was deeper in females, but overall right side was deeper 52(51.5\%) as shown in table 3.

Table 3: Showing the depth of olfactory fossa in both gender.

\begin{tabular}{|c|c|c|c|}
\hline Gender & $\begin{array}{c}\text { Deeper right } \\
\text { olfactory fossa } \\
\text { deep }\end{array}$ & $\begin{array}{c}\text { Deeper left } \\
\text { olfactory } \\
\text { fossa }\end{array}$ & $\begin{array}{c}\text { Bilateral } \\
\text { symmetrical }\end{array}$ \\
\hline Male $(n=51)$ & $29(56.9 \%)$ & $21(41.2 \%)$ & $1(1.9 \%)$ \\
\hline Female $(n=50)$ & $23(46 \%)$ & $26(52 \%)$ & $1(2 \%)$ \\
\hline Total $(n=101)$ & $52(51.5 \%)$ & $47(46.6 \%)$ & $2(1.9 \%)$ \\
\hline
\end{tabular}

The height of the LLCP on right side was $3.331+/-5.010 \mathrm{~mm}$ whereas on left side it was $2.845+/-1.084 \mathrm{~mm}$.

The figure 2 and 3 show the different variations of Keros' classification.

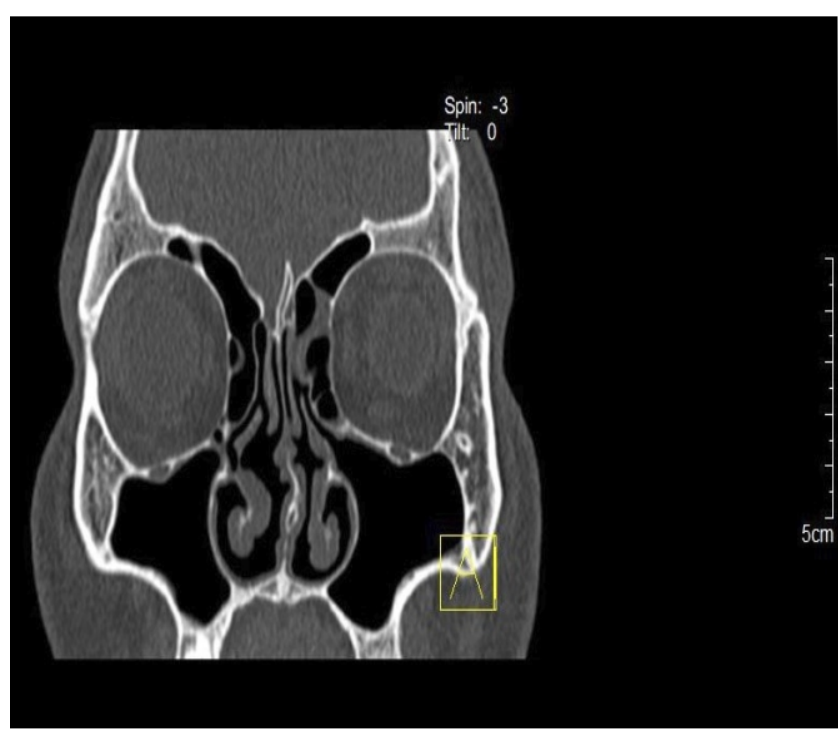

Figure 2 : Showing the Keros' variation I (left side) and II (right side)

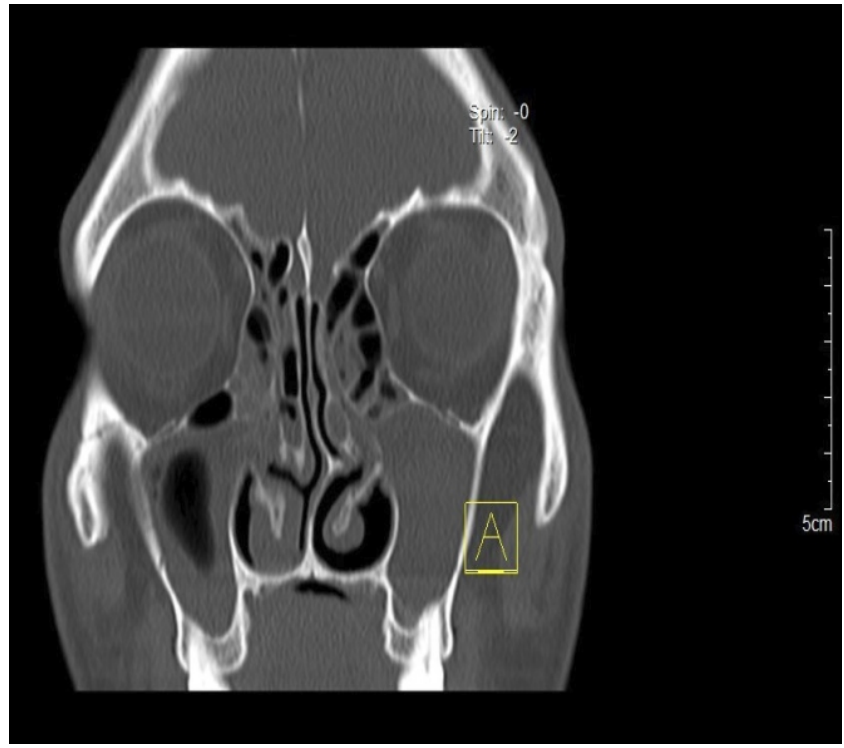

Figure 3: Showing the Keros' variation III (left side)

Table 4: Showing the variations of Keros' types in different studies.

\begin{tabular}{|l|l|c|c|c|}
\hline Authors & Country & $\begin{array}{c}\text { Keros' Type } \\
\text { I (\%) }\end{array}$ & $\begin{array}{c}\text { Keros' Type } \\
\text { II (\%) }\end{array}$ & $\begin{array}{c}\text { Keros'Type } \\
\text { III(\%) }\end{array}$ \\
\hline Shama et al (1) & Egypt & 56.5 & 40.5 & 3.0 \\
\hline Souza et al (2) & Brazil & 26.3 & 73.3 & 0.5 \\
\hline Paber et al (4) & Philippine & 81.8 & 17.7 & 0.5 \\
\hline Solares et al (5) & USA & 83.0 & 15.0 & 2.0 \\
\hline Keros P (6) & Germany & 26.3 & 73.3 & 0.5 \\
\hline Rathnakar et al (8) & India & 28.0 & 70.5 & 1.5 \\
\hline Athamneh et al(10) & Jordan & 70.5 & 22.0 & 7.5 \\
\hline Murthy et al (12) & India & 19.5 & 71.5 & 9.0 \\
\hline Kaplanoglu et al (13) & Turkey & 13.4 & 76.1 & 10.5 \\
\hline Sahin et al (14) & Turkey & 10.0 & 61.0 & 29.0 \\
\hline Erdem et al (15) & Turkey & 8.1 & 59.6 & 32.3 \\
\hline Bista et al (16) & Nepal & 86.0 & 12.0 & 2.0 \\
\hline Elwany et al (17) & Egypt & 42.5 & 56.8 & 0.7 \\
\hline Alazzawi et al (18) & Malaysia & 80.0 & 20.0 & 0 \\
\hline Nitinavakarn et al (19) & Thailand & 11.9 & 68.8 & 19.3 \\
\hline Ali et al (20) & India & 20.0 & 78.7 & 1.3 \\
\hline Jang et al (21) & Korea & 30.5 & 69.5 & 0 \\
\hline Adeel et al (9) & Pakistan & 29.9 & 49.4 & 20.8 \\
\hline Erdogan et al (22) & Turkey & 10.0 & 67.72 & 22.28 \\
\hline Our study & Nepal & 86.1 & 13.4 & 0.5 \\
\hline
\end{tabular}

\section{DISCUSSION}

The endoscopic sinus surgery is done mainly to remove the disease within the sinus and improve the ventilation. ${ }^{9}$ This procedure is widely accepted for clearing the disease. The risk of iatrogenic injury to skull base area during surgery is always there and the most vulnerable area is LLCP, as it is the thinnest bone. ${ }^{10}$ So, it is important to look for the LLCP and olfactory fossa depth by CT imaging of nose and paranasal sinuses. Coronal CT scan is the best to visualize the olfactory fossa depth. We have performed our study as per the variations formulated by Keros' on $1962 .{ }^{6}$

As per Keros' study in 450 skulls, type I has a depth of $1-3 \mathrm{~mm}$ and is seen in $12 \%$ patients, type II has a depth of $4-7 \mathrm{~mm}$ and is seen in $70 \%$ patients, whereas type III has a depth of $8-16 \mathrm{~mm}$ and is seen in $18 \%$ patients. ${ }^{6}$ 
Our study showed that Keros' type I was the most common whereas type III was the least common with $86.1 \%$ patients falling in type I and only $0.5 \%$ in type III. So, it is somehow safe from the surgeon's point of view to do surgery in Keros' type I population. The distribution of Keros' variation in different studies in the literature and comparison with our study is shown in table 4. We have found 19 studies of Keros' variation in different countries and most of them had type II as the commonest variation (13 out of 19 studies) whereas 6 out of 19 studies had type I as the commonest variation as in our study. So, there is marked variation in Keros' types in the literature.

Regarding the gender distribution, in male and female both type I was more common both in right and left, whereas type III was only seen in right side in male. The reason behind large group falling under type I in our study could be because of taking up to $3.99 \mathrm{~mm}$ in type I unlike up to $3 \mathrm{~mm}$ in original Keros' classification and another may be because of developmental anatomical variation within the population and also due to difference in the extent of pneumatisation of the ethmoidal labyrinth and frontal sinus. $^{11}$

Our study showed that the height of LLCP on right side was $3.331+/-5.010 \mathrm{~mm}$, whereas on left side, it was $2.845+/-$ $1.084 \mathrm{~mm}$.This differs from other studies as most of the studies had LLCP of $>4 \mathrm{~mm} .^{10,12-22}$ The difference in height could be because of variation in ethmoidal roof configuration between different population and another reason might be use of different measurement methods. In our study we had taken the infraorbital foramen as a reference point. Different literature has suggested this reference point as of relevant anatomic value during endoscopic middle meatal antrostomy as it helps in telling about the position of the ethmoidal roof. ${ }^{14}$

Our study also showed that the depth of the olfactory fossa was more on right in males whereas in females it was more on left side. We could not find any reason for it. However the possible explanation could be hormonal factors in development of craniofacial asymmetry. The literature has also shown variation in depth of olfactory fossa either on left or right with no consistency.

But the overall depth of olfactory fossa was more on the right side $(51.5 \%)$ in our study. The significance of our results showed that skull base injury with cerebrospinal fluid leaks occur more frequently when endoscopic sinus

\section{REFERENCES}

1. Shama SAM, Montaser M. Variations of the height of the ethmoid roof among Ezyptian adult population: MDCT study. The Ezyptian Journal of Radiology and Nuclear Medicine 2015; 46: 929-36. http://dx.doi.org/10.1016/j.ejrnm.2015.07.013

2. Souza SA, Souza MMA, Idagawa M, Wolosker AMB, Ajzen SA. Computed tomography assessment of the ethmoid roof: a relevant region at risk in endoscopic sinus surgery. Radiol Bras 2008; 41(3):143-7. http://dx.doi.org/10.1590/S0100-398420080 00300003

3. Luong A, Marple BF. Sinus surgery: indications and techniques. Clin Rev Allergy Immunol 2006;30:217-22. PMID:16785592 surgery is perform on right side as mentioned in literature. ${ }^{23,26}$ So, we have to be very careful while performing surgery on right side.

In our study the type I Keros' variation was the most common. Therefore it is safer for the surgeon to perform endoscopic sinus surgery in type I population like ours as the iatrogenic risk of skull base injury is minimal.

\section{CONCLUSION}

1. The study on variation of Keros' classification is mainly to avoid injury in ethmoidal roof during sinus surgery.

2. In our study, type I is the most common Keros' type prevalent and the least prevalent is the type III.

3. A deep olfactory fossa is more common on right as compared to left in our population.

4. Careful and precise assessment of CT nose and PNS is a must prior to sinus surgery in order to avoid serious iatrogenic injury.

\section{RECOMMENDATION}

The type I Keros' variation is the most common and a deep olfactory fossa is more common on right as compared to left. However this study is single institutional, so we recommend the multi-institutional study in the different regions of Nepal which will give better idea regarding the distribution of Keros' variation of olfactory fossa.

\section{LIMITATION OF THE STUDY}

The main limitation of the study is sample size and short duration of study.

\section{ACKNOWLEDGEMENT}

None

\section{CONFLICT OF INTEREST}

None.

\section{FINANCIALDISCLOSURE}

None.

4. Paber JAL, Cabato MSD, Villarta RL, Hernandez JG.Radiographic analysis of the ethmoid roof based on KEROS classification among filipinos. Philippine J Otolaryngol Head Neck Surg 2008;23(1):15-9.

5. Solares CA, Lee WT, Batra PS, Citardi MJ. Lateral lamella of the cribriform plate. Software-enabled computed tomographic analysis and its clinical relevance in skull base surgery. Arch Otolaryngol Head Neck Surg 2008;134(3):285-9. DOI:10.1001/ archotol.134.3.285

6. Keros P. On the practical value of differences in the level of the lamina cribrosa of the ethmoid. Z Laryngologie, Rhinologie, Otologie Ihre Grenzgeb 1962;41:808-13. PMID:14032071 
7. Ulualp SO. Complications of endoscopic sinus surgery: appropriate management of complications. Curr Opin Otolaryngol Head Neck Surg 2008;16:252-9. DOI:10.1097/MOO.0b013e3282fdc3b2

8. Rathnakar P, Shrinath D, Kamath P. Computed tomographic study of depth of anterior skull base in dakshina kannada population. Int J Anat Res 2016;4(3):2738-42. DOI: 10.16965/ijar.2016.320

9. Adeel M, Ikram M, Rajput MS, Arain A, Khattak YJ. Lateral lamella of the cribriform plate: software - enabled computed tomographic analysis and its clinical relevance in endoscopic sinus surgery. Surg Radiol Anat 2013;35(9):843-7. doi: 10.1007/s00276-013-1106-4

10. Athamneh I, Hazaimeh B, Shawaqfeh J, Hani MB, Altamimi A. Keros classification among Jordanian population. JRMS 2015;22(3):69-72.

11. Krmpotic-Nemanic J, Vinter I,Judas M. Transformation of the shape of the ethmoid bone during the course of life. Eur Arch Otorhinolaryngol 1997;254:347-9. https://doi.org/ 10.1007/ BF02630727

12. Murthy AV, Santosh B. A study of clinical significance of the depth of olfactory fossa in patients undergoing endoscopic sinus surgery. Indian J Otolaryngol Head Neck Surg 2017;69(4):514-22. DOI:10.1007/s12070-017-1229-8

13. Kaplanoglu H, Kaplanoglu V, Dilli A, Toprak U, Hekimoglu B. An analysis of the anatomic variations of the paranasal sinuses and ethmoid roof using computed tomography. Eurasian J Med 2013;45(2):115-25. DOI:10.5152/eajm.2013.23

14. Sahin C, Yılmaz YF, Titiz A, O"zcan M, O"zlu gedik S, U"nal A.Analysis of ethmoid roof and cranial base in Turkish population. $K B B$ ve $B B C$ Dergisi 2007;15:1-6.

15. Erdem G, Erdem T, Miman MC, Ozturan O. A radiological anatomic study of the cribriform plate compared with constant structures. Rhinology 2004;42:225-9. PMID:15626256

16. Bista M, Maharjan M, Kafle P, Shrestha S, KC T. Computed tomographic assessment of lateral lamella of cribriform plate and comparison of depth of olfactory fossa. J Nepal Med Assoc 2010;49(178):92-5. PMID:21485590

17. Elwany S, Medanni A, Eid M, Aly A, El-Daly A, Ammar SR. Radiological observations on the olfactory fossa and ethmoid roof. J Laryngol Otol 2010;124:1251-6. DOI:10.1017/ S0022215 110001313
18. Alazzawi S, Omar R, Rahmat K, Alli K. Radiological analysis of the ethmoid roof in the Malaysian population. Auris Nasus Larynx 2012;39:393-6. DOI:10.1016/j.anl.2011.10.002

19. Nitinavakarn B, Thanaviratananich S, Sangsilp N. Anatomical variations of the lateral nasal wall and paranasal sinuses: a CT study for endoscopic sinus surgery in Thai patients. J Med Assoc Thai 2005; 88:763-8. PMID:16083216

20. Ali A, Kurien M, Shyamkumar NK, Selvaraj. Anterior skull base: High risk areas in endoscopic sinus surgery in chronic rhinosinusitis: A computed tomographic analysis. Indian J Otolaryngol Head Neck Surg 2005;57:5-8. https://doi.org/10.1007/BF02907616

21. Jang YJ, Park HM, Kim HG. The radiographic incidence of bony defects in the lateral lamella of the cribriform plate. Clin Otolaryngol Allied Sci 1999;24:440-2. PMID: 10542927

22. Erdogan S, Keskin IG, Topdag M, Ozturk M, Sari F, Mutlu F. Ethmoid roof radiology; analysis of lateral lamella of cribriform plate. Otolaryngol Pol 2015; 69(6):53-7. DOI:10.5604/ 00306657. 1184543

23. Dessi P, Moulin G, Triglia JM, Zanaret M, Cannoni M. Difference in the height of the right and left ethmoidal roofs: a possible risk factor for ethmoidal surgery. Prospective study of $150 \mathrm{CT}$ scans. J Laryngol Otol 1994;108:261-2. PMID:8169516

24. Arikan OK, Unal B, Kazkayasi M, Koc C. The analysis of anterior skullbase from two different perspectives: coronal and reconstructed sagittal computed tomography. Rhinology 2005;43: 115-20. PMID:16008066

25. Lebowitz RA, Terk A, Jacobs JB, Holliday RA. Asymmetry of the ethmoid roof: analysis using coronal computed tomography. Laryngoscope 2001;111:2122-4. DOI:10.1097/00005537200112000-00007

26. Bumm K, Heupel J, Bozzato A, Iro H, Hornung J. Localization and infliction pattern of iatrogenic skull base defects following endoscopic sinus surgery at a teaching hospital. Auris Nasus Larynx 2009;36(6):671-6. DOI: 10.1016/j.anl.2009.03.004. 